\title{
The value of routine chest radiographs after minimally invasive cardiac surgery: an observational cohort study
}

\author{
Martijn Tolsma ${ }^{1 *}$, Mohamed Bentala $^{2}$, Peter MJ Rosseel ${ }^{3}$, Bastiaan M Gerritse ${ }^{3}$, Homme AJ Dijkstra $^{4}$, Paul GH Mulder ${ }^{5}$
} and Nardo JM van der Meer ${ }^{3,6}$

\begin{abstract}
Background: Chest radiographs (CXRs) are obtained frequently in postoperative cardiac surgery patients. The diagnostic and therapeutic efficacy of routine CXRs is known to be low and the discussion regarding the safety of abandoning these CXRs after cardiac surgery is still ongoing. We investigated the value of routine CXRs directly after minimally invasive cardiac surgery.

Methods: We prospectively included all patients who underwent minimally invasive cardiac surgery by port access, ministernotomy or bilateral video-assisted thoracoscopy (VATS) in the year 2012. A direct postoperative CXR was performed on all patients at ICU arrival. All CXR findings were noted, including whether they led to an intervention or not. The results were compared to the postoperative CXR results in patients who underwent conventional cardiac surgery by full median sternotomy over the same period.

Main results: A total of 249 consecutive patients were included. Most of these patients underwent valve surgery, rhythm surgery or a combination of both. The diagnostic efficacy for minor findings was highest in the port access and bilateral VATS groups (56\% and $63 \%$ versus $28 \%$ and $45 \%)(p<0.005)$. The diagnostic efficacy for major findings was also higher in these groups ( $8.9 \%$ and $11 \%$ versus $4.3 \%$ and $3.8 \%)(p=0.010)$. The need for an intervention was most common after minimally invasive surgery by port access, although this difference was not statistically significant $(p=0.056)$.

Conclusions: The diagnostic efficacy of routine CXRs performed after minimally invasive cardiac surgery by port access or bilateral VATS is higher than the efficacy of CXRs performed after conventional cardiac surgery. A routine CXR after these procedures should still be considered.
\end{abstract}

Keywords: Chest radiographs, Cardiac surgery, Intensive care unit

\section{Background}

Chest radiographs (CXRs) are obtained frequently for intensive care unit (ICU) patients, on a routine basis, after a change in clinical situation or after surgery and other certain procedures. Multiple investigators have studied the clinical value of routine CXRs following central venous catheterization, endotracheal intubation and chest tube placement or removal [1-12]. Others have studied the value of daily routine CXRs in a mixed ICU population or in mechanically ventilated patients only [13-22] The

\footnotetext{
* Correspondence: martijntolsma@gmail.com

'Department of Anesthesiology \& Intensive Care, Isala Klinieken, Dokter van Heesweg 2, 8025, AB Zwolle, The Netherlands

Full list of author information is available at the end of the article
}

diagnostic and therapeutic efficacy of these routine CXRs is known to be low [1-3,6-9,11,13,14,16-19,22]. Investigators comparing a routine CXR strategy with an on-demand CXR strategy were not able to show any difference in outcome measures [23-29], but a more recent meta-analysis by Ganapathy et al. indicated that study populations were small and that eventually missed findings in a restrictive strategy were not evaluated frequently enough [27]. Moreover, the discussion regarding specific indications of CXRs in critically ill patients and the safety of abandoning routine CXRs is still ongoing [25-27].

In accordance with the results of general studies on this topic, the clinical value of routine chest radiographs after cardiac surgery is reported to be low [30-34]. Abandoning 
routine CXRs in this population may only be safe when patients at risk are identified and certain indications of CXRs are stated. Minimally invasive cardiac surgery patients represent a population that might benefit from routine CXRs after surgery. Minimally invasive cardiac surgery has become increasingly popular over the past decade and is currently safe and effective [35-37]. Surgical access is obtained by (antero)lateral thoracotomy (port access), video-assisted thoracoscopy (VATS), ministernotomy or a parasternal approach. The procedures involved concern mainly valve surgery and rhythm surgery. The aims of minimally invasive surgery are to reduce blood loss, the number of reoperations, postoperative pain and the length of ICU stay and to promote a quick recovery and provide a cosmetically better result [35-38]. To our knowledge, there are no reports on CXR findings after minimally invasive cardiac surgery. Hypothetically, there are some findings that can be diagnosed by a postoperative CXR. These results might be related to the place of surgical access (pneumothorax, subcutaneous emphysema), temporary one lung ventilation technique (atelectasis), less surgical field visualization and hemostasis (haemothorax) or the need for invasive device placement (pulmonary artery catheter, temporary transvenous pacing wire). We performed a study on the efficacy of CXRs obtained directly after minimally invasive cardiac surgery.

\section{Methods}

This prospective, observational, single-center study was performed on a tertiary 24-bed closed format ICU, admitting medical, surgical and cardiothoracic surgical patients. The medical staff consisted of 12 intensivists and 8 residents in ICU medicine. The study protocol was approved by the local ethics committee of the Amphia Hospital (AMOA; Adviescommissie Mensgebonden Onderzoek Amphia, mr. F. de Haan). This is the hopsital where the study was conducted. The need for informed consent was waived because no interventions were applied to the patients apart from the common and current local practice. All patient data were obtained anonymously.

The study population was a part of another prospective study on CXR findings in all cardiosurgical patients admitted in the year 2012. We selected all consecutive patients who underwent minimally invasive cardiac surgery during this year, concerning patients for valve surgery, rhythm surgery or a combination of both. The patients were divided by the type of surgical access; port access, ministernotomy or bilateral VATS. All patients who underwent cardiac surgery by conventional full median sternotomy over the same period were used as a control group. Patients were admitted to the ICU directly after surgery. For all minimally invasive surgery patients, a CXR was obtained routinely at ICU arrival. For patients who underwent conventional surgery, a CXR was performed on-demand postoperative or routinely on the morning of the first postoperative day.

Demographic data and surgery characteristics were collected for all patients. The mean age and the median duration of ICU stay were calculated. All CXRs were assessed both by a radiologist and an ICU physician. CXR findings were classified according to the overview presented in Table 1 and were divided into minor findings and major findings. Only new findings were incorporated into analysis, and abnormalities already present on a preoperative CXR were not taken into consideration again.

All CXR abnormalities were noted. For major abnormalities it was also noted whether this abnormality led to an intervention. Possible interventions were chest tube placement, reposition of invasive devices, diuretic therapy, echocardiographic assessment and re-operation. The proportion of CXRs that showed minor and major findings was calculated, as was the proportion of CXRs with findings that led to a subsequent intervention. The diagnostic efficacy (the number of abnormalities divided by the total number of CXRs) and therapeutic efficacy (the number of interventions based on CXR abnormalities divided by the total number of CXRs) were also calculated. Finally, the CXR results of minimally invasive cardiac surgery patients were compared to the postoperative CXR results for patients who underwent cardiac surgery by conventional median sternotomy in the same period.

Data analysis was performed using IBM SPSS Statistics v21.0 for Windows. Differences in the percentages of findings and interventions were tested using Fisher's exact test. Other differences were tested using a two sample t-test or a Mann Whitney test where appropriate. A p-value below 0.05 was used to denote significance.

Table 1 Classification of radiologic findings

\begin{tabular}{ll}
\hline Minor findings $^{1}$ & Major findings $^{2}$ \\
\hline Minimal pleural effusion & Severe pleural effusion \\
Minimal pulmolectasis & Large atelectasis \\
Small consolidation & Severe pulmonary congestion \\
& Large consolidation \\
& Malposition of invasive devices \\
& Widened mediastinum \\
& Large subcutaneous emphysema \\
& Haemothorax \\
& Pneumothorax \\
& Pneumomediastinum \\
& Pneumopericardium \\
& Free air under diaphragm
\end{tabular}

'Involvement of less than one lobe, and/or judged 'normal postoperative'. ${ }^{2}$ Involvement of one lobe or more, and/or judged 'no normal postoperative finding'. 
Table 2 Baseline data of the study population and procedures, divided by type of surgical access

\begin{tabular}{|c|c|c|c|c|c|}
\hline & PA & MS & BV & CS & $\mathbf{p}$ \\
\hline Patients, n & 124 & 69 & 56 & 1102 & \\
\hline Gender, male, n (\%) & $68(55)$ & $34(49)$ & $41(73)$ & $809(73)$ & $<0.005$ \\
\hline Age, years, mean $\pm S D$ & $68 \pm 10$ & $69 \pm 12$ & $61 \pm 8$ & $69 \pm 9$ & $<0.005$ \\
\hline Length of ICU stay, days, mean & $1.6(1-9)$ & $1.5(1-20)$ & $1.1(1-4)$ & $2.0(1-66)$ & 0.007 \\
\hline \multicolumn{6}{|l|}{ (range) } \\
\hline Length of ICU stay 1 day, n (\%) & $93(75)$ & $63(91)$ & $53(95)$ & $847(77)$ & $<0.005$ \\
\hline \multicolumn{6}{|l|}{ Procedures; n (\%) } \\
\hline CABG & - & - & - & $655(49)$ & $<0.005$ \\
\hline CABG with valve surgery & - & - & - & $177(13)$ & $<0.005$ \\
\hline CABG with rhythm surgery & - & - & - & $21(2)$ & 0.345 \\
\hline Valve surgery & $78(63)$ & $69(100)$ & & $140(13)$ & $<0.005$ \\
\hline Valve surgery with aortic surgery & - & - & - & $42(4)$ & 0.016 \\
\hline Valve surgery and rhythm surgery & $43(35)$ & - & - & $32(3)$ & $<0.005$ \\
\hline Aortic surgery & - & - & - & $24(2)$ & 0.230 \\
\hline Rhythm surgery & - & - & $56(100)$ & - & $<0.005$ \\
\hline Other surgery & $3(2,4)$ & - & - & $11(1)$ & 0.389 \\
\hline
\end{tabular}

PA = Port Access; MS = Mini-sternotomy; BV = Bilateral Video Assisted Thoracoscopy; $C S=$ Conventional Sternotomy; $\mathrm{n}=$ Number; SD = Standard Deviation; $\mathrm{ICU}=$ Intensive Care Unit; IQR = Interquartile Range; CABG = Coronary Artery Bypass Graft; VATS = Video Assisted Thoracoscopy.

\section{Results}

Table 2 shows the baseline characteristics of the study population. A total of 249 consecutive patients who underwent minimally invasive cardiac surgery by port access $(n=124)$, mini-sternotomy $(n=69)$ or bilateral VATS $(n=56)$ were included. Most of these patients underwent valve surgery, rhythm surgery or a combination of both. Their CXR results were compared to the CXR results of 1102 patients who underwent conventional cardiac surgery in the same period. The most frequent procedure in this population was coronary artery bypass grafting (CABG) eventually combined with valve surgery or rhythm surgery. Patients who had cardiac surgery by port access or mini-sternotomy were less frequently male (55\% and $49 \%$ compared to $73 \%)(\mathrm{p}<0.005)$. Patients in the bilateral VATS group were younger $(61 \pm 8$ years compared to $69 \pm 9$ years) $(\mathrm{p}<0.005)$. The mean length of ICU stay was shorter for all minimally invasive surgery groups when compared to that of the conventional cardiac surgery group (1.6, 1.5 and 1.1 days compared to 2.0 days $)(\mathrm{p}=0.007)$.

Table 3 shows a comparison of the diagnostic and therapeutic efficacies for CXRs performed after the different types of minimally invasive cardiac surgery and CXRs performed after conventional cardiac surgery. The diagnostic efficacy for minor findings was highest in the port access and bilateral VATS groups (56\% and 63\% compared to $28 \%$ and $45 \%$ in the mini-sternotomy and conventional surgery groups) $(\mathrm{p}<0.005)$. The diagnostic efficacy for major findings was also higher in the port access and bilateral VATS groups (8.9\% and 11\% compared to $4.3 \%$ and $3.8 \%)(p=0.010)$. The need for an intervention was most common after minimally invasive surgery by port access ( $4.8 \%$ of cases compared to $1.5 \%$ of cases after conventional surgery), although this difference was not statistically significant $(\mathrm{p}=0.056)$.

An overview of minor postoperative CXR findings is shown in Table 4. Pleural effusion, atelectasis and

Table 3 Comparison of diagnostic and therapeutic CXR values between different types of surgery

\begin{tabular}{|c|c|c|c|c|c|}
\hline & $\begin{array}{l}P A \\
(n=124)\end{array}$ & $\begin{array}{l}\text { MS } \\
(n=69)\end{array}$ & $\begin{array}{l}\text { BV } \\
(n=56)\end{array}$ & $\begin{array}{l}\text { CS } \\
(n=1102)\end{array}$ & p \\
\hline CXRs with any finding, n (\%) & $80(65)$ & $22(32)$ & $41(73)$ & $540(49)$ & $<0.005$ \\
\hline CXRs with minor findings only, $\mathrm{n}(\%)^{1}$ & $79(56)$ & $19(28)$ & $35(63)$ & $498(45)$ & $<0.005$ \\
\hline CXRs with major findings, $\mathrm{n}(\%)^{1}$ & $11(8.9)$ & $3(4.3)$ & $6(11)$ & $42(3.8)$ & 0.010 \\
\hline CXRs with subsequent intervention, $\mathrm{n}(\%)^{2}$ & $6(4.8)$ & $0(0)$ & $0(0)$ & $17(1.5)$ & 0.056 \\
\hline
\end{tabular}

CXR = Chest Radiograph; PA = Port Access; MS = Mini-sternotomy; BV = Bilateral Video Assisted Thoracoscopy; CS = Conventional Sternotomy; $\mathrm{n}=$ Number. 
Table 4 Minor CXR findings

\begin{tabular}{|c|c|c|c|c|c|}
\hline & $\begin{array}{l}P A \\
(n=124)\end{array}$ & $\begin{array}{l}\text { MS } \\
(n=69)\end{array}$ & $\begin{array}{l}\text { BV } \\
(n=56)\end{array}$ & $\begin{array}{l}\text { CS } \\
(n=1102)\end{array}$ & $\mathrm{p}$ \\
\hline \multicolumn{6}{|l|}{ Finding; n (\%) } \\
\hline Pleural effusion & $22(18)$ & $3(4.3)$ & $12(21)$ & $171(16)$ & 0.019 \\
\hline Atelectasis & $36(29)$ & $6(8.7)$ & $22(39)$ & $257(23)$ & $<0.005$ \\
\hline Pulmonary congestion & $12(9.7)$ & $11(14)$ & $19(34)$ & $173(16)$ & $<0.005$ \\
\hline Consolidation & $19(15)$ & $4(5.8)$ & $10(18)$ & $63(5.7)$ & $<0.005$ \\
\hline
\end{tabular}

$\mathrm{PA}=$ Port Access; MS = Mini-sternotomy; BV = Bilateral Video Assisted Thoracoscopy; $C S=$ Conventional Sternotomy; $C X R=$ Chest Radiograph; $n=$ Number.

consolidation were observed more frequent after minimally invasive surgery by port access and bilateral VATS $(\mathrm{p}=0.019, \mathrm{p}<0.005$ and $\mathrm{p}<0.005)$, whereas pleural effusion and atelectasis were observed less frequently in the mini-sternotomy group. Minor pulmonary congestion was observed significantly more frequently in the bilateral VATS group ( $<<0.005)$.

The major findings are presented in Table 5. The values shown are small, and only severe pulmonary congestion, large consolidation and large subcutaneous emphysema were observed statistically more frequently in the port access or bilateral VATS groups $(\mathrm{p}=0.013, \mathrm{p}=0.024$ and $\mathrm{p}=0.016$ ). A pneumothorax, a haemothorax and malposition of invasive devices were also observed more frequently in all minimally invasive surgery groups, although this finding was not significant.

\section{Discussion}

We observed that routine CXRs obtained after minimally invasive cardiac surgery by port access or bilateral VATS have a higher diagnostic value than CXRs performed after cardiac surgery by mini-sternotomy or conventional full median sternotomy. The high diagnostic efficacy for minor findings in all groups (40-60\%) is comparable to the results reported in previous studies for cardiac surgery patients and studies performed in a general ICU population.
$[22,33]$ We observed diagnostic efficacies of $8.9 \%$ and $11 \%$ for major findings after minimal invasive cardiac surgery by port access and bilateral VATS, which is clearly higher than what has been observed in more recent studies on the efficacy of chest radiographs after conventional cardiac surgery or for critically ill patients in generally $[18,31,33]$. A low therapeutic efficacy ( $1 \%$ to $4 \%$ ) does correspond with previous findings $[16,18,33]$. We only observed a higher therapeutic value for CXRs after cardiac surgery by port access (4.8\%).

The difference between patients who underwent minimally invasive cardiac surgery by port access or bilateral VATS and other cardiosurgical patients, as mentioned above, most likely be related to the complications of these surgical procedures. We were able to confirm a more frequent presence of atelectasis following a one lung ventilation technique. In addition, although not statistically significant, we did observe the relatively frequent presence of a pneumothorax, haemothorax and malposition of invasive devices after minimally invasive procedures. These results may be related to the place of surgical access, difficult hemostasis and the need for invasive device placement.

Because the discussion regarding the indications of CXRs in ICU patients and the specific clinical situations in which routine CXRs should still be performed is still

Table 5 Major CXR findings

\begin{tabular}{|c|c|c|c|c|c|}
\hline & $\begin{array}{l}P A \\
(n=124)\end{array}$ & $\begin{array}{l}\text { MS } \\
(n=69)^{\prime}\end{array}$ & $\begin{array}{l}\text { BV } \\
(n=56)\end{array}$ & $\begin{array}{l}\text { CS } \\
(n=1102)\end{array}$ & $p$ \\
\hline \multicolumn{6}{|l|}{ Finding; $n$} \\
\hline Large pleural effusion/haemothorax & $2(1.6)$ & $1(1.4)$ & $0(0)$ & $5(0.5)$ & 0.204 \\
\hline Large atelectasis & $0(0)$ & $0(0)$ & $0(0)$ & $2(0.2)$ & 1.000 \\
\hline Severe pulmonary congestion & $2(1.6)$ & $0(0)$ & $1(1.8)$ & $1(0.1)$ & 0.013 \\
\hline Large consolidation & $2(1.6)$ & $0(0)$ & $0(0)$ & $0(0)$ & 0.024 \\
\hline Malposition invasive devices & $3(2.4)$ & $2(2.9)$ & $1(1.8)$ & $10(0.9)$ & 0.104 \\
\hline Widened mediastinum & $1(0.8)$ & $0(0)$ & $2(3.6)$ & $13(1.2)$ & 0.299 \\
\hline Large subcutaneous emphysema & $1(0.8)$ & $0(0)$ & $1(1.8)$ & $0(0)$ & 0.016 \\
\hline Pneumothorax & $3(2.4)$ & $2(2.9)$ & $1(1.8)$ & $10(0.9)$ & 0.104 \\
\hline Pneumopericardium & $0(0)$ & $0(0)$ & $0(0)$ & $2(0,2)$ & 1.000 \\
\hline
\end{tabular}

$\mathrm{PA}=$ Port Access; MS = Mini-sternotomy; BV = Bilateral Video Assisted Thoracoscopy; CS = Conventional Sternotomy; CXR = Chest Radiograph; $n=$ Number. 
ongoing, our results may be of interest. In our opinion, and in agreement with our findings, there is still a place for routine CXRs directly after minimally invasive cardiac surgery by port access or bilateral VATS. This is in contradiction to patients after uncomplicated conventional cardiac surgery or minimally invasive surgery by ministernotomy.

Our study is limited by the fact that it was a singlecenter study and that it was performed according to a routine CXR strategy protocol. A postoperative CXR was performed anyway for every patient. The study is also limited by the fact that we used an observational cohort study design without randomization or blinding. On the other hand, according to our design, no findings could be missed and the frequency of eventual subsequent interventions was evaluated.

\section{Conclusion}

Routine CXRs performed after minimally invasive cardiac surgery by port access or bilateral VATS have a higher diagnostic efficacy than CXRs performed after cardiac surgery by mini-sternotomy or conventional full median sternotomy. A routine CXR after these procedures should still be considered.

\section{Abbreviations}

CXR: Chest radiograph; ICU: Intensive care unit; VATS: Video assisted thoracoscopy; IBM: International business machines; SPSS: Statistical package for the social sciences; CABG: Coronary artery bypass grafting.

\section{Competing interests}

The authors declared that they have no competing interests.

\section{Authors' contributions}

MT participated in the study design, data acquisition, data analysis, data interpretation and drafting the manuscript. MB, PR, BG and $\mathrm{HD}$ participated in the study design, data acquisition and revising the manuscript. PM participated in the data analysis and revising the manuscript. NM participated in the study design, data acquisition, data analysis, data interpretation, drafting and revising the manuscript. All authors have read and approved the final manuscript.

\section{Acknowledgements}

The study was funded by the Amphia Hospital, Department of Intensive Care, Breda, The Netherlands, and by the TiasNimbas Business School, Tilburg University, Tilburg, The Netherlands.

\section{Author details}

'Department of Anesthesiology \& Intensive Care, Isala Klinieken, Dokter van Heesweg 2, 8025, AB Zwolle, The Netherlands. ${ }^{2}$ Department of Cardiothoracic Surgery, Amphia Hospital, Molengracht 21, 4818, CK Breda, The Netherlands. ${ }^{3}$ Department of Anesthesiology \& Intensive Care, Amphia Hospital, Molengracht 21, 4818, CK Breda, The Netherlands. 'Department of Radiology, Amphia Hospital, Molengracht 21, 4818, CK Breda, The Netherlands. ${ }^{5}$ Amphia Hospital, Amphia Academy, Molengracht 21, 4818, CK Breda, The Netherlands. ${ }^{6}$ TiasNimbas Business School, Tilburg University, Warandelaan 2, 5037, AB Tilburg, The Netherlands.

Received: 1 July 2014 Accepted: 21 October 2014

Published online: 11 November 2014

\section{References}

1. Lessnau KD: Is chest radiography necessary after uncomplicated insertion of a triple-lumen catheter in the right internal jugular vein, using the anterior approach? Chest 2005, 127(1):220-223.
2. Lucey B, Varghese JC, Haslam P, Lee MJ: Routine chest radiographs after central line insertion: mandatory postprocedural evaluation or unnecessary waste of resources? Cardiovasc Intervent Radiol 1999, 22(5):381-384.

3. Sanabria A, Henao C, Bonilla R, Castrillón C, Cruz H, Ramírez W, Navarro P, González M, Díaz A: Routine chest roentgenogram after central venous catheter insertion is not always necessary. Am J Surg 2003, 186(1):35-39.

4. Abood GJ, Davis KA, Esposito TJ, Luchette FA, Gamelli RL: Comparison of routine chest radiograph versus clinician judgment to determine adequate central line placement in critically ill patients. J Trauma 2007, 63(1):50-56

5. Brunel W, Coleman DL, Schwartz DE, Peper E, Cohen NH: Assessment of routine chest roentgenograms and the physical examination to confirm endotracheal tube position. Chest 1989, 96(5):1043-1045.

6. Lotano R, Gerber D, Aseron C, Santarelli R, Pratter M: Utility of postintubation chest radiographs in the intensive care unit. Crit Care 2000, 4(1):50-53.

7. Whitehouse MR, Patel A, Morgan JA: The necessity of routine postthoracostomy tube chest radiographs in post-operative thoracic surgery patients. Surgeon 2009, 7(2):79-81.

8. Eisenberg RL, Khabbaz KR: Are chest radiographs routinely indicated after chest tube removal following cardiac surgery? AJR Am J Roentgenol 2011, 197(1):122-124.

9. Khan T, Chawla G, Daniel R, Swamy M, Dimitri WR: Is routine chest X-ray following mediastinal drain removal after cardiac surgery useful? Eur J Cardiothorac Surg 2008, 34(3):542-544.

10. McCormick JT, O'Mara MS, Papasavas PK, Caushaj PF: The use of routine chest X-ray films after chest tube removal in postoperative cardiac patients. Ann Thorac Surg 2002, 74(6):2161-2164

11. Palesty JA, McKelvey AA, Dudrick SJ: The efficacy of X-rays after chest tube removal. Am J Surg 2000, 179(1):13-16.

12. Sepehripour $A H$, Farid $S$, Shah $R$ : Is routine chest radiography indicated following chest drain removal after cardiothoracic surgery? Interact Cardiovasc Thorac Surg 2012, 14(6):834-838.

13. Silverstein DS, Livingston DH, Elcavage J, Kovar L, Kelly KM: The utility of routine daily chest radiography in the surgical intensive care unit. J Trauma 1993, 35(4):643-646.

14. Fong Y, Whalen GF, Hariri RJ, Barie PS: Utility of routine chest radiographs in the surgical intensive care unit. A prospective study. Arch Surg 1995 , 130(7):764-768.

15. Brainsky A, Fletcher RH, Glick HA, Lanken PN, Williams SV, Kundel HL: Routine portable chest radiographs in the medical intensive care unit: effects and costs. Crit Care Med 1997, 25(5):801-805.

16. Graat ME, Choi G, Wolthuis EK, Korevaar JC, Spronk PE, Stoker J, Vroom MB, Schultz MJ: The clinical value of daily routine chest radiographs in a mixed medical-surgical intensive care unit is low. Crit Care 2006, 10(1):R11.

17. Graat ME, Kroner A, Spronk PE, Korevaar JC, Stoker J, Vroom MB, Schultz MJ: Elimination of daily routine chest radiographs in a mixed medical-surgical intensive care unit. Intensive Care Med 2007, 33(4):639-644.

18. Hendrikse KA, Gratama JW, Hove W, Rommes JH, Schultz MJ, Spronk PE: Low value of routine chest radiographs in a mixed medical-surgical ICU. Chest 2007, 132(3):823-828.

19. Kager LM, Kröner A, Binnekade JM, Gratama JW, Spronk PE, Stoker J, Vroom $M B$, Schultz MJ: Review of a large clinical series: the value of routinely obtained chest radiographs on admission to a mixed medical-surgical intensive care unit. J Intensive Care Med 2010, 25(4):227-232.

20. Hall JB, White SR, Karrison T: Efficacy of daily routine chest radiographs in intubated, mechanically ventilated patients. Crit Care Med 1991, 19(5):689-693.

21. Bhagwanjee S, Muckart DJ: Routine daily chest radiography is not indicated for ventilated patients in a surgical ICU. Intensive Care Med 1996, 22(12):1335-1338.

22. Clec'h C, Simon P, Hamdi A, Hamza L, Karoubi P, Fosse JP, Gonzalez F, Vincent $F$, Cohen $Y$ : Are daily routine chest radiographs useful in critically ill, mechanically ventilated patients? A randomized study. Intensive Care Med 2008, 34(2):264-270

23. Krinsley JS: Test-ordering strategy in the intensive care unit. J Intensive Care Med 2003, 18(6):330-339.

24. Krivopal M, Shlobin OA, Schwartzstein RM: Utility of daily routine portable chest radiographs in mechanically ventilated patients in the medical ICU. Chest 2003, 123(5):1607-1614.

25. Hejblum G, Chalumeau-Lemoine L, loos V, Boëlle PY, Salomon L, Simon T, Vibert JF, Guidet B: Comparison of routine and on-demand prescription 
of chest radiographs in mechanically ventilated adults: a multicentre, cluster-randomised, two-period crossover study. Lancet 2009, 374(9702):1687-1693.

26. Oba Y, Zaza T: Abandoning daily routine chest radiography in the intensive care unit: meta-analysis. Radiology 2010, 255(2):386-395.

27. Ganapathy A, Adhikari NK, Spiegelman J, Scales DC: Routine chest x-rays in intensive care units: a systematic review and meta-analysis. Crit Care 2012, 16(2):R68.

28. Kröner A, Binnekade JM, Graat ME, Vroom MB, Stoker J, Spronk PE, Schultz MJ: On-demand rather than daily-routine chest radiography prescription may change neither the number nor the impact of chest computed tomography and ultrasound studies in a multidisciplinary intensive care unit. Anesthesiology 2008, 108(1):40-45.

29. Mets O, Spronk PE, Binnekade J, Stoker J, de Mol BA, Schultz MJ: Elimination of daily routine chest radiographs does not change on-demand radiography practice in post-cardiothoracic surgery patients. J Thorac Cardiovasc Surg 2007, 134(1):139-144.

30. Hornick PI, Harris P, Cousins C, Taylor KM, Keogh BE: Assessment of the value of the immediate postoperative chest radiograph after cardiac operation. Ann Thorac Surg 1995, 59(5):1150-1153. discussion 1153-4.

31. Karthik S, O'Regan DJ: An audit of follow-up chest radiography after coronary artery bypass graft. Clin Radiol 2006, 61(7):616-618.

32. Rao PS, Abid Q, Khan K, Meikle RJ, Natarajan KM, Morritt GN, Wallis J, Kendall SW: Evaluation of routine postoperative chest X-rays in the management of the cardiac surgical patient. Eur J Cardiothorac Surg 1997, 12(5):724-729.

33. Tolsma M, Kröner A, van den Hombergh CL, Rosseel PM, Rijpstra TA, Dijkstra HA, Bentala M, Schultz MJ, van der Meer NJ: The clinical value of routine chest radiographs in the first 24 hours after cardiac surgery. Anesth Analg 2011, 112(1):139-142.

34. Graham RJ, Meziane MA, Rice TW, Agasthian T, Christie N, Gaebelein K, Obuchowski NA: Postoperative portable chest radiographs: optimum use in thoracic surgery. J Thorac Cardiovasc Surg 1998, 115(1):45-50. discussion $50-2$.

35. Schmitto JD, Mokashi SA, Cohn LH: Minimally-invasive valve surgery. J Am Coll Cardiol 2010, 56(6):455-462.

36. Suri RM, Thalji NM: Minimally invasive heart valve surgery: how and why in 2012. Curr Cardiol Rep 2012, 14(2):171-179.

37. Czesla M, Götte JM, Doll N: How to establish video assisted, minimally invasive mitral valve surgery. Heart 2012, 98(15):1172-1178.

38. Balaguer JM, Umakanthan R, Leacche M, Byrne JG: Minimally invasive cardiac surgery. Curr Probl Surg 2012, 49(9):529-549.

doi:10.1186/s13019-014-0174-9

Cite this article as: Tolsma et al:: The value of routine chest radiographs after minimally invasive cardiac surgery: an observational cohort study. Journal of Cardiothoracic Surgery 2014 9:174.

\section{Submit your next manuscript to BioMed Central and take full advantage of:}

- Convenient online submission

- Thorough peer review

- No space constraints or color figure charges

- Immediate publication on acceptance

- Inclusion in PubMed, CAS, Scopus and Google Scholar

- Research which is freely available for redistribution

Submit your manuscript at www.biomedcentral.com/submit
Ciomed Central 